\title{
Proportion of Visceral leishmaniasis and human immune deficiency virus co- infection among clinically confirmed visceral leishmaniasis patients at the endemic foci of the Amhara National Regional State, north-west Ethiopia
}

\author{
Mulat Yimer ${ }^{1, ~ *}$, Bayeh Abera ${ }^{1}$, Wondemagegn Mulu ${ }^{1}$, Yohannes Zenebe ${ }^{1}$, Belay Bezabih ${ }^{2}$ \\ ${ }^{1}$ BDU, College of Medicine and Health Sciences,Ethiopia \\ ${ }^{2}$ Amhara National Regional Health Bureau, Ethiopia
}

\section{Email address:}

yimermulat@gmail.com(M. Yimer), bayeabera15@gmail.com(B. Abera),wondem_32@yahoo.com(W. Mulu), yohabt22@gmail.com(Y. Zenebe), fiametaye@yahoo.com(B. Bezabih)

To cite this article:

Mulat Yimer, Bayeh Abera, Wondemagegn Mulu, Yohannes Zenebe, Belay Bezabih. Proportion of Visceral Leishmaniasis and Human Immune Deficiency Virus Co- Infection among Clinically Confirmed Visceral Leishmaniasis Patients at the Endemic Foci of the Amhara National Regional State, North-West Ethiopia. American Journal of Biomedical and Life Sciences. Vol. 2, No. 1, 2014, pp. 1-7.

doi: 10.11648/j.ajbls.20140201.11

\begin{abstract}
In East Africa, especially in Ethiopia, the proportion of VL patients with HIV co-infection has increased, despite a decline in the numbers of co-infected patients in Europe. The Metema and Humera lowland areas in the north-west are particularly associated with high HIV co-infection rates, ranging from $18 \%$ to $31 \%$ of the cases. Therefore, the aim of this study was to determine the proportion of VL/HIV co- infection among clinically confirmed VL patients in the endemic foci of the Amhara Region. Institutional based cross- sectional study was conducted from February to July, 2013 on the proportion of VL/HIV co- infection among clinically confirmed VL patients. For the study, a total of 409 participants who were clinically confirmed VL patients were participated in four selected endemic foci (Libokemkem, Belessa, Metema and west Armachiho). Proportionate allocation was used to determine the number of patients involved in each selected endemic foci. Of the 409 clinically confirmed VL patients, the overall proportion of VL/ HIV co-infection was 74 (18.1\%). Among the VL endemic foci, proportion of VL/ HIV co- infection was highest in Abdrafi 69 (93.2\%) followed by Metema 5 (6.8\%.). However, in Addis Zemen and Belessa showed nil (0\%). Among the study participants, males were more VL/HIV co-infected $74(19.4 \%)$ than females $(0 \%)(\mathrm{P}<0.012)$ and the age groups from 21-35 were the highest infected group $68(16.6 \%)(\mathrm{P}<0.001)$. Moreover, those patients who came from rural areas were more VL/ HIV co-infected $46(35.1 \%)$ than urban dwellers $28(23.1 \%)(\mathrm{P}<0.001)$. Furthermore, daily labourers were the highest infected group $60(57.1 \%)(\mathrm{P}<0.001)$ and those who had no formal education had more VL/HIV co-infected $62(24.6 \%)(\mathrm{P}$ $<0.001)$ than those who had formal education. The overall proportion of VL/ HIV co-infection was still high and among the VL endemic foci, proportion of VL/ HIV co- infection was highest in Abdrafi followed by Metema. However, in Addis Zemen and Belessa showed nil. Therefore, face to face health education is mandatory to create awareness about VL, HIV and VL/HIV co -infection and its consequence at the Kebele level.
\end{abstract}

Keywords: Visceral Leishmaniasis, Human Immunodeficiency Virus, VL Endemic Foci, Amhara Region

\section{Introduction}

Visceral leishmaniasis (VL) or Kala-azar (KA) is a severe systemic disease caused by protozoan parasites of the Leishmania donovani complex [1]. It also appears as an opportunistic parasitic disease associated with human immunodeficiency virus (HIV) infection and other immune suppressed patients [2]. It is transmitted by female phlebotomine sandflies during blood feeding, needed for egg maturation [3].

It is known that VL has been reported from at least 40 areas in Ethiopia [4] and is highly endemic and growing health problems, which is caused by $L$. donovani donovani [5]. However, the most important VL endemic areas are found in the North-West Ethiopia (Metema and Humera 
lowlands), accounting for $60 \%$ of the cases in the country [6].

Although it is widely distributed throughout the lowland areas of the country, outbreaks of VL has occurred in the highlands e.g., in Libokemkem district (south Gondar), has claimed the lives of hundreds, before medical intervention [7]. Moreover, a few cases of VL have been also found in the Belessa highlands [8]. In the Amhara National Regional State, it is endemic in: Metemma, Quara, Fogera, Libokemkem, West Belessa, Tach Armachiho, West Armachiho, and East Belessa [9].

The pandemicity of HIV has modified the natural history of VL and it increases the risk of developing VL by a factor of between 100 and 1000 in endemic areas, reduces the likelihood of therapeutic response, and greatly increases the probability of relapse [10]. It also increases the risks of VL treatment failure, drug toxicity and mortality [11]. In the mean time, VL promotes clinical progression of HIV and the development of acquired immunodeficiency syndrome (AIDS)-defining conditions. Because, the two diseases target similar immune cells and together they exert a synergistic damaging effect on the cellular immune response [5].

In East Africa, especially in Ethiopia, the proportion of VL patients with HIV co-infection has increased, despite a decline in the numbers of co-infected patients in Europe because of the increased use of highly active antiretroviral therapy [12]. For instance, in Humera (north-west Ethiopia), the proportion of VL patients co- infected with HIV increased from $18.5 \%$ in $1998-99$ to $40 \%$ in 2006 [10].

Moreover, with the HIV epidemic, the burden of VL has dramatically increased in Ethiopia over the last 10 years [13]. In 1996, 7 cases of VL and HIV co-infection were reported [14]; in 2002, among 103 VL cases about 51\% were HIV positive [15].

Furthermore, the Metema and Humera lowlands in the northwest are particularly associated with high HIV co-infection rates, ranging from $18 \%$ to $31 \%$ of the cases [16]. Despite this figure, inadequate information exists on the rates of VL/ HIV co infection in the endemic foci especially, in the study sites. Therefore, this study was conducted to determine the rate of VL / HIV co infection among clinically VL confirmed patients in the endemic foci of the Amhara Region.

\section{Materials and Methods}

\subsection{Study Period and Area}

Institutional based cross- sectional study was conducted from February to July, 2013.

Four visceral leishmaniasis endemic foci [Libokemkem, Belessa, Metema and West Armachiho] were selected for this study. Libokemkem, district has a total population of 198,435 , of whom 100,987 are men and 97,448 women; 22,054 or $11.11 \%$ are urban inhabitants. In Belessa, district has a population of 140,214 in 28,046 households, of whom
72,535 were men and 67,679 women; 5,857 or $4.18 \%$ of its population were urban dwellers. In Metema, the district has a population of 110,231 ; of whom 58,734 are male and 51, 497 are females. In West Armachiho, the district has a total population of 31,730 , of whom 17,400 are men and 14,330 women; 15,075 or $47.5 \%$ are urban inhabitants. [17].

Source and study populations were all clinically suspected VL patients and all clinically confirmed VL patients who were attending in the selected health institutions in the VL endemic foci respectively. Study participants were all clinically confirmed VL patients who were volunteered to participate in the study. Moreover, both independent (socio-demographic characteristics like: Sex, age, residence, occupation, and educational status) and dependent (VL/HIV co- infection) variables were used. Finally, all clinically suspected VL patients were included and known HIV positive patients were excluded.

\subsection{Sample Size Determination and Sampling Technique}

The sample size for this study was calculated by single proportion formula at $95 \%$ confidence interval (CI) level ( $Z$ $(1-\alpha ́ / 2)=1.96)$ and using $41 \%$ of VL/HIV co-infection conducted at Gondar University teaching hospital [13]. Then the sample size was calculated as $\mathrm{n}=\left[\begin{array}{ll}\mathrm{Z} & 1-\mathrm{a} / 2\end{array}\right]^{2}$ $\mathrm{P}(1-\mathrm{p}] / \mathrm{d}^{2}$, Where: $\mathrm{n}=$ sample size, $\mathrm{P}=$ population proportion, $\mathrm{Z} 1-\mathrm{a} / 2=\mathrm{CI}$ of $95 \%, \mathrm{~d}=$ Marginal error to be tolerated. By adding $10 \%$ of contingency 409 patients were included in our study and assuming that the sample includes $50 \%$ of VL endemic foci and hence, using the simple random sampling method, $4 \mathrm{VL}$ endemic foci (Libokemkem, Belessa, Metema and west Armachiho) were selected.

Then, proportionate allocation was employed to know sample size of each stratum based on the annual rates of clinically suspected VL patients who were attending at each health institution. Hence, the number of clinically confirmed VL patients participated in the study were: 66 for Metema hospital, 107 for Addis Zemen, 27 for Belessa and 209 for Abdrafi health centers, having a total of 409 patients.

\subsection{Sample Collection and Processing}

The clinician or the health officer examined those who were suspicion of VL infections according to the WHO criteria. Then the socio demographic characteristics were filled by the clinician or health officer during physical examination.

Finally, tests were requested by the clinician or health officer and the patient was referred to the volunteer counseling and testing centre (VCT) for counseling of HIV and finally to the laboratory. Then, from the laboratory, about $3 \mathrm{ml}$ of blood was drawn from each patient for both types of tests (VL and HIV). Then, using rK39 kit (rk-39 dipsticks, (Dia MedIT Leish) from DiaMed AG, Cressiers / Morat (Switzerland) for VL and HIV rapid testing algorithm KHB (Bio-Engineering, Shanghai, Kehua). If the 
khb result was reactive SAT PAK (Chemobiodiagnostic, INC, Medfold, Newyork) for HIV, was investigated according to the test kit instruction. Then, discordant results were resolved with Unigold (Trinity Biotech PLC, Bary Ireland) and the result was sent to the clinician or to the health officer and at the same time recorded on the log book for research.

\subsection{Data Analysis}

Data was checked for completeness, coded and analysed using SPSS version 16. For descriptive statistics, frequency, percentage, mean and standard deviation were used. While for categorical analysis, Chi-square was used to describe the association between variables and $\mathrm{p}<0.05$ was considered statistically significant for comparison. Finally, the following two operational definitions were used.

Clinically suspected VL patients: are patients with fever for $\geq 2$ weeks, splenomegally or lymphadenopathy, and weight loss.

Clinically confirmed VL patients: are patients with fever for $\geq 2$ weeks, splenomegally or lymphadenopathy, and weight loss), and a positive rK39 rapid diagnostic test (DiaMed-IT-Leish) for Leishmania antibodies, after exclusion of malaria and bacterial infections.

\subsection{Ethical Consideration}

Ethical clearance was obtained from Regional health Bureau and district offices of each study sites, before the study commences. All those study subjects were asked to obtain written consents. The study subjects were informed about the study in their language, including the purpose of the study, their benefit. For those who were illiterate, the written consent was read and only patients who were sign in the written consent was included in the study.

Moreover, confidentiality of any information related with clinical and laboratory data/result was guaranteed. To ensure it, information was identified using codes, and patient's name was not be used. Clinically VL suspected patients will be referred to the VCT center for HIV counseling and finally: VL, HIV and VL / HIV positive results were referred to the physician and/ or health officer for treatment.

\section{Results}

In this study, of the 409 clinically confirmed VL patients, the male to female ratio were $14: 1$ and majority of the patients were male $382(93.4 \%)$. The mean ages of the participants were 31 years with a standard deviation of 15 . Regards to residence, most of the patients came from other areas for treatment 157 (38.4\%) followed by rural areas of the VL endemic foci accounting for 131 (32\%). Concerning the occupation of patients who were participated in the study, most of them were farmers $184(45 \%)$ and the least were military personnel $3(0.7 \%)$. Moreover, regarding educational status, most of them had no formal education $252(61.6 \%)$ (Table 1).

Table 1 Socio demographic characteristics of patients in the visceral leishmaniasis endemic foci of the Amhara Region, north -west Ethiopia from February to July, 2013.

\begin{tabular}{|c|c|c|c|c|c|}
\hline \multirow{2}{*}{ Characteristic } & \multicolumn{3}{|c|}{ Visceral leishmaniasis endemic foci } & & \multirow[t]{2}{*}{ Total } \\
\hline & Addis Zemen & Belessa & Metema & West Armachiho & \\
\hline & No (\%) & No $(\%)$ & \multirow{2}{*}{$\begin{array}{l}\text { No }(\%) \\
(n=66)\end{array}$} & No $(\%)$ & \multirow{2}{*}{$\begin{array}{l}\text { No }(\%) \\
(n=409)\end{array}$} \\
\hline Sex & $(\mathrm{n}=107)$ & $(\mathrm{n}=27)$ & & $(\mathrm{n}=209)$ & \\
\hline Male & $98(25.7)$ & $22 \quad(5.8)$ & $60 \quad(15.7)$ & $202(52.9)$ & $382(93.4)$ \\
\hline Female & $9 \quad(33.3)$ & $5(18.5)$ & $6 \quad(22.2)$ & $7 \quad(25.9)$ & $27 \quad(6.6)$ \\
\hline Total & $107(26.2)$ & $27(6.6)$ & $66(16.1)$ & $209(51.1)$ & $409(100)$ \\
\hline \multicolumn{6}{|l|}{ Age in years } \\
\hline$\leq 5$ & $12 \quad(54.5)$ & $2(9.1)$ & $1(4.5)$ & $7(31.8)$ & $22 \quad(5.4)$ \\
\hline $6-10$ & $11 \quad(44)$ & $4 \quad(16)$ & $4(16)$ & $6(24)$ & $25 \quad(6.1)$ \\
\hline $11-15$ & $11 \quad(44)$ & $2(8)$ & $6(24)$ & $6 \quad(24)$ & $25 \quad(6.1)$ \\
\hline $16-20$ & $(30.7)$ & $6 \quad(8)$ & $20(26.7)$ & $26 \quad(34.7)$ & $75 \quad(18.3)$ \\
\hline $21-25$ & $(16.3)$ & $9 \quad(5.9)$ & $21(13.7)$ & $98 \quad(64.1)$ & $153 \quad(37.4)$ \\
\hline $26-30$ & (19.7) & $3 \quad(4.5)$ & (6) & $46 \quad(69.7)$ & (16.1) \\
\hline $31-35$ & (13) & 0 & $(8.7)$ & $15 \quad(65.2)$ & $(5.6)$ \\
\hline$\geq 36$ & $(39.1)$ & $1 \quad(4.3)$ & $8 \quad(34.8)$ & $5(21.7)$ & $23 \quad(5.6)$ \\
\hline Total & $107 \quad(26.2)$ & $27 \quad(6.6)$ & $66 \quad(16.1)$ & $209 \quad(51.1)$ & $409 \quad(100)$ \\
\hline \multicolumn{6}{|l|}{ Residence } \\
\hline Urban & $19 \quad(15.7)$ & $10(8.3)$ & $32 \quad(26.4)$ & $60(49.6)$ & $121(29.6)$ \\
\hline Rural & $27 \quad(20.6)$ & $17 \quad(13)$ & $4 \quad(3.1)$ & $100 \quad(76.3)$ & $131 \quad(32)$ \\
\hline *Other sites & $61 \quad(38.9)$ & 0 & $30 \quad(19.1)$ & $49 \quad(31.2)$ & $157(38.4)$ \\
\hline Total & $107 \quad(26.2)$ & $27(6.6)$ & $66 \quad(16.1)$ & $209(51.1)$ & $409 \quad(100)$ \\
\hline Occupation & & & & & \\
\hline
\end{tabular}


4 Mulat Yimer et al:: Proportion of Visceral Leishmaniasis and Human Immune Deficiency Virus Co- Infection among Clinically Confirmed Visceral Leishmaniasis Patients at the Endemic Foci of the Amhara National Regional State, North-West Ethiopia

\begin{tabular}{|c|c|c|c|c|c|}
\hline Daily laborer & $1 \quad(0.9)$ & 0 & 0 & $104 \quad(99)$ & $105(25.7)$ \\
\hline Farmer & $66 \quad(35.9)$ & $12 \quad(6.5)$ & $35 \quad(19)$ & $71(38.6)$ & $184 \quad(45)$ \\
\hline Military personnel & 0 & 0 & $2(66.7)$ & $1 \quad(33.3)$ & $3 \quad(0.7)$ \\
\hline Student & $27 \quad(30)$ & $12 \quad(13.3)$ & $26 \quad(28.9)$ & $25 \quad(27.8)$ & $90 \quad(22)$ \\
\hline$* *$ Others & $13 \quad(48)$ & $3 \quad(11.1)$ & $3 \quad(11.1)$ & $8 \quad(29.6)$ & $27 \quad(6.6)$ \\
\hline Total & $107 \quad(26.2)$ & $27 \quad(6.6)$ & $66 \quad(16.1)$ & $209(51.1)$ & $409(100)$ \\
\hline \multicolumn{6}{|l|}{ Education } \\
\hline No formal & $60(23.8)$ & $15 \quad(6)$ & $37(14.7)$ & $140(55.6)$ & $252(61.6)$ \\
\hline $1-4$ & $8 \quad(21.6)$ & $2 \quad(5.4)$ & $4 \quad(10.8)$ & $23 \quad(6.2)$ & $37 \quad(9)$ \\
\hline $5-8$ & $12 \quad(38.7)$ & $3 \quad(6.4)$ & $5 \quad(16.1)$ & $11(35.5)$ & $31(7.6)$ \\
\hline $9-12$ & $27 \quad(31.4)$ & $7 \quad(8.1)$ & $18(20.9)$ & $34 \quad(39.5)$ & $86 \quad(21)$ \\
\hline Diploma \& above & 0 & 0 & $2 \quad(66.7)$ & $1 \quad(33.3)$ & $3 \quad(0.7)$ \\
\hline Total & $107(26.2)$ & $27 \quad(6.6)$ & $66 \quad(16.1)$ & $209(51.1)$ & $409(100)$ \\
\hline
\end{tabular}

*Patients came from other areas for treatment to the visceral leishmaniasis endemic foci

**Patients who were other than the specified occupation

Of the 409 clinically confirmed VL patients, the overall proportion of VL/ HIV co- infection was 74 (18.1\%). Among the VL endemic foci, proportion of VL/ HIV coinfection was highest in Abdrafi 69 (93.2\%) followed by Metema 5 (6.8\%.). However, in Addis Zemen and Belessa showed nil $(0 \%)$. Of 409 VL patients who were agreed to HIV testing, $74(18.1 \%)$ were HIV positive having the same value as VL/ HIV co-infection (Table 2). Of those with co-infections, 74 (19.4\%) were males (Table 3).

Table 2 proportion of VL/ HIV co- infection among VL endemic foci of the Amhara Region north- west Ethiopia from February to July, 2013.

\begin{tabular}{|c|c|c|c|c|c|}
\hline \multirow[b]{3}{*}{ Characteristic } & \multicolumn{4}{|c|}{ Clinically confirmed VL cases in endemic foci } & \multirow[t]{2}{*}{ Total } \\
\hline & Addis Zemen & Belessa & Metema & West Armachiho & \\
\hline & $\begin{array}{l}\text { No }(\%) \\
(n=107)\end{array}$ & $\begin{array}{l}\text { No }(\%) \\
(\mathrm{n}=27)\end{array}$ & $\begin{array}{l}\text { No }(\%) \\
(\mathrm{n}=66)\end{array}$ & $\begin{array}{l}\text { No }(\%) \\
(\mathrm{n}=209)\end{array}$ & $\begin{array}{l}\text { No }(\%) \\
(\mathrm{n}=409)\end{array}$ \\
\hline Hiv positive & 0 & 0 & $5 \quad(6.8)$ & $69 \quad(93.2)$ & $74 \quad(18.1)$ \\
\hline *VL/HIV co-infected & 0 & 0 & $5 \quad(6.8)$ & $69 \quad(93.2)$ & $74 \quad(18.1)$ \\
\hline HIV negative & $107 \quad(31.9)$ & $27 \quad(8.5)$ & $61 \quad(18.2)$ & $140 \quad(41.5)$ & $335(81.9)$ \\
\hline Total & $107(26.2)$ & $27 \quad(6.6)$ & $66(16.1)$ & $209 \quad(51.1)$ & $409 \quad(100)$ \\
\hline
\end{tabular}

*Visceral leishmaniasis and human immunodeficiency virus co- infection

An attempt had been made to determine the association between socio demographic characteristics and VL/ HIV co -infection and it was found that males were highly infected $74(19.4 \%)$ as compared to females $(0 \%)(\mathrm{P}<0.012)$. The age groups from $21-25,26-30$ and $31-35$ were more infected $35(22.9 \%), 23(34.8 \%)$ and $10(50 \%)$ respectively $(\mathrm{P}<0.001)$. Patients who came from rural areas of the VL endemic foci were more infected 46 (35.1\%) than urban dwellers 28 (23.1\%) $(\mathrm{P}<0.001)$. Moreover, Daily labourers were the highest infected group $60(57.1 \%)$ followed by farmers $12(6.5 \%)(\mathrm{P}<0.001)$. Furthermore, patients who had no formal education were more VL/HIV co-infected 62 $(24.6 \%)$ than to those who had formal education $(\mathrm{P}<0.001)$ (Table 3).

Table 3 Association between socio demographic characteristics and VL/HIV co-infection in the VL endemic foci of the Amhara Region north -west Ethiopia from February to July, 2013.

\begin{tabular}{|c|c|c|c|c|}
\hline \multirow[b]{2}{*}{ Characteristic } & \multicolumn{2}{|c|}{ VL/ HIV co-infection } & Total & \multirow[t]{2}{*}{$P$ value } \\
\hline & Yes & No & & \\
\hline \multirow{2}{*}{ Sex } & No $(\%)$ & No (\%) & No (\%) & \\
\hline & $(\mathrm{n}=74)$ & $(\mathrm{n}=335)$ & $(\mathrm{n}=409)$ & \\
\hline Male & $74 \quad(19.4)$ & $308 \quad(80.6)$ & $382 \quad(93.4)$ & \multirow{3}{*}{$<0.012$} \\
\hline Female & 0 & $27 \quad(100)$ & $27 \quad(6.6)$ & \\
\hline Total & $74 \quad(18.1)$ & $335 \quad(81.9)$ & $409 \quad(100)$ & \\
\hline \multicolumn{5}{|l|}{ Age } \\
\hline$\leq 5$ & 0 & $22 \quad(100)$ & $22 \quad(5.4)$ & \multirow{2}{*}{$<0.001$} \\
\hline $6-10$ & 0 & $25 \quad(100)$ & $25 \quad(6.1)$ & \\
\hline
\end{tabular}




\begin{tabular}{|c|c|c|c|c|}
\hline $11-15$ & 0 & $25 \quad(100)$ & $25 \quad(6.1)$ & \\
\hline $16-20$ & 0 & $75 \quad(100)$ & $75 \quad(18.3)$ & \\
\hline $21-25$ & $35 \quad(22.9)$ & $118 \quad(77.1)$ & $153 \quad(37.4)$ & \\
\hline $26-30$ & $23 \quad(34.8)$ & $43 \quad(65.1)$ & $66 \quad(16.1)$ & \\
\hline $31-35$ & $10 \quad(50)$ & $10 \quad(50)$ & $20 \quad(4.9)$ & \\
\hline$\geq 36$ & $6 \quad(26)$ & $17 \quad(73.9)$ & $23 \quad(5.6)$ & \\
\hline Total & $74 \quad(18.1 \quad)$ & $335 \quad(81.9 \quad)$ & $409 \quad(100)$ & \\
\hline \multicolumn{5}{|l|}{ Residence } \\
\hline Urban & $28 \quad(23.1)$ & $93 \quad(76.9)$ & $121 \quad(29.6)$ & \multirow{4}{*}{$<0.001$} \\
\hline Rural & $46 \quad(35.1)$ & $85 \quad(64.9)$ & $131 \quad(32.1)$ & \\
\hline *Other areas & 0 & $157 \quad(100)$ & $157 \quad(38.4)$ & \\
\hline Total & $74 \quad(18.1)$ & $335 \quad(81.9)$ & $409 \quad(100)$ & \\
\hline \multicolumn{5}{|l|}{ Occupation } \\
\hline Daily labourer & $60 \quad(57.1)$ & $45 \quad(42.9)$ & $105 \quad(25.7)$ & \multirow{6}{*}{$<0.001$} \\
\hline Farmer & $12 \quad(6.5)$ & $172 \quad(93.5)$ & $184 \quad(45)$ & \\
\hline Military personnel & 0 & $(100)$ & $(0.7)$ & \\
\hline Student & $2 \quad(2.2)$ & $88 \quad(97.8)$ & $90 \quad(22)$ & \\
\hline **Others & 0 & $27 \quad(100)$ & $27 \quad(6.6)$ & \\
\hline Total & $74 \quad(18.1)$ & $335 \quad(81.9)$ & $409 \quad(100)$ & \\
\hline \multicolumn{5}{|l|}{ Educational status } \\
\hline No formal & $62 \quad(24.6)$ & $190 \quad(75.4)$ & $252 \quad(61.6)$ & \multirow{6}{*}{$<0.001$} \\
\hline $1-4$ & $6 \quad(16.2)$ & $31 \quad(83.8)$ & $37 \quad(9.1)$ & \\
\hline $5-8$ & $6 \quad(19.4)$ & $25 \quad(80.6)$ & $31 \quad(7.6)$ & \\
\hline $9-12$ & 0 & $86 \quad(100)$ & $86 \quad(21)$ & \\
\hline Diploma \& above & 0 & $3 \quad(100)$ & $3 \quad(0.7)$ & \\
\hline Total & $74 \quad(18.1)$ & $335 \quad(81.9)$ & $409 \quad(100)$ & \\
\hline
\end{tabular}

* Patients who came from other areas for treatment to the VL endemic foci

**Patients who had other than the specified occupation

\section{Discussion}

In this study, of the 409 clinically confirmed VL patients, the overall proportion of VL/ HIV co -infection was 74 (18.1\%) (Table 2) and this study was inconsistent with the study done in Gondar University Hospital 78 (41\%) [11]. This might be explained by time limitation and exclusion of Humera Hospital in the present study. Among the VL endemic foci, proportion of VL/ HIV co- infection was highest in Abdrafi 69 (93.2\%) followed by Metema 5 $(6.8 \%$.). However, in Addis Zemen and Belessa showed nil $(0 \%)$ (Table 2). This is because these two foci are particularly associated with high HIV co-infection rates, ranging from $18 \%$ to $31 \%$ of the cases [16]. Or this might be due to high prevalence of HIV in Abdrafi and Metema as compared to Adds Zemen and Belessa.

Of the $382(93.4 \%)$ clinically confirmed VL males, 74(19.4\%) were VL/ HIV co-infected. While, of the 27 (6.6\%) clinically confirmed VL females, no VL/HIV co-infection was seen $(\mathrm{P}<0.012)$ (Table 3). This might be related with more migration of males as a seasonal daily laborer to the high VL/ HIV endemic foci [7]. On the other hand, of the 409 clinically confirmed VL cases, 382 (93.4\%) were males and $27(6.6 \%)$ were females. This difference might be resulted from male's practice of sleeping outside, often in proximity to guard dogs (reservoir host) to protect their cattle from theft [18]. This increased the chance of males infected by Phlebotous orientalis (the most probable vector of VL in the north- west and northern part of Ethiopia) [1].

Of the 409 clinically confirmed VL cases, the age groups from 21-35 was more VL/ HIV co - infected 68 (16.6\%) (P $<0.001$ ) (Table 3). This might be due to this age group was mobile and also they moved to the highly VL/HIV coinfected area of Metema and Humera lowlands as a daily laborer [16].

Regards to residence of patients who were participated in the study, those patients who came from rural areas of the VL endemic foci were more VL/HIV co-infected 46 (35.1\%) than urban dwellers $28(23.1 \%)(\mathrm{P}<0.001)$ (Table 3). This might be resulted from awareness difference. Because people in urban areas had more likely chance of getting information towards VL, HIV and VL/HIV co-infection as compared to rural dwellers. Of the 409 clinically confirmed VL cases, $121(29.6 \%)$ were urban dwellers and 131 $(32.1 \%)$ were rural dwellers. This difference might be because people in the rural areas most of the time didn't use bed nets [18]. Or this finding may reflect the male tendency to sleep outdoors to guard their cattle and this suggests increment in transmission [7].

Concerning the occupation of participants who were involved in the study, it was found that daily labourers were 
the highest VL/ HIVco- infected group $60 \quad(57.1 \%)$ followed by farmers $12(6.5 \%)(\mathrm{P}<0.001)$ (Table 3$)$. This might be due to migration of daily labourers to the Metema and Humera lowlands in the northwest areas particularly associated with high VL/ HIV co-infection rates, [16]. Moreover, lack of awareness in farmers towards VL/HIV co-infection.

Regards to educational status of study participants, those who had no formal education were more VL/HIV coinfected $62(24.6 \%)$ than to those who had formal education( $\mathrm{P}<0.001$ ) ( Table 3 ). This difference might be explained as because education is essential to create awareness towards the prevention of VL, HIV and VL/HIV co-infection. Overall, all the specified socio demographic characteristics had statistically significant association with VL/HIV co-infection.

\section{Conclusion}

In this study, the overall proportion of VL/ HIV co-infection was still high and among the VL endemic foci, rate of VL/ HIV co- infection was highest in Abdrafi followed by Metema. However, in Addis Zemen and Belessa showed nil.

Among the study participants, males were more VL/HIV co-infected than females and the age groups from 21-35 were the highest infected group. Moreover, those patients who came from rural areas were more VL/ HIV co-infected than urban dwellers. Furthermore, daily labourers were the highest infected group and those who had no formal education had more VL/HIV co-infected than those who had formal education of the north- west endemic foci of the Amhara Region. Based on the above conclusion, we recommended that face to face health education is mandatory to create awareness about VL, HIV and VL/HIV co-infection and its consequence at the Kebele level.

\section{Competing Interests}

The author(s) declare that they have no competing interests.

\section{Acknowledgments}

We would like to express great thanks to ENHAT-CS/MSH for financing this research and we also would like to thank for all study participants who were involved in this study. Finally, we would like to thank for Dr. Belaynew Wassie for his unreserved assistance starting from data collections up to the final write up of this research.

\section{References}

[1] Gelanew T, Cruz I, Kuhls K, Alvar J, Canavate C, Hailu A, Schonian G. Multilocus microsatellite typing revealed high genetic variability of Leishmania donovani strains isolated during and after a Kala-azar epidemic in Libo Kemkem district, Northwest Ethiopia. Microb Infec, vol.13, pp. 595-601, 2011.

[2] Emami MM, Yazdi M. Entomological survey of phlebotomine sandflies (Diptera: Psychodidae) in a focus of visceral leishmaniasis in central Iran. Vect borne Dis, vol. 45, pp.38-43, 2008.

[3] Andrade BB, Oliveira C I, Brodskyn C I, Barral A, Barral-Netto M. Role of sand fly saliva in human and experimental leishmaniasis: current insights. Scand J Immunol, vol. 66, pp.122-127, 2007.

[4] Hailu A, Gebre-Michael T, Berhe N, Balkew M. Leishmaniasis in Ethiopia. In: Berhane Y., Hailemariam D. and Kloos H. first eds. The ecology of health and disease in Ethiopia. Addis Ababa: Shaman Books. 2006; pp, 615- 634.

[5] WHO. Risk factors for Leishmaniasis. Wkly epidemiol record, vol. 44 pp.365-372, 2002.

[6] Hailu A, Mucciob T D, Abebea T, Hunegnaw M, Kagerd P A, Marina Gramicciab M. Isolation of Leishmania tropica from an Ethiopian cutaneous leishmaniasis patient. Trans Roy Soc Trop Med Hyg, vol.100, pp. 53-58, 2006.

[7] Alvar J, Bashaye S, Aragaw D, Cruz I, Aparicio P, Kassa A, Orfanos G, Parreno F, Babaniyi O, Gudeta N, Canavate C, Bern C. Kalaazar outbreak in Libokemekm, Ethiopia: epidemiologic and parasitological assessment. Am J Trop Med Hyg, vol. 77, pp. 275-282, 2007.

[8] Lindtjorn B. Kala-azar in Sidamo, South Ethiopia. Ethiop Med J, vol.18, pp. 99-100, 1980.

[9] Amahara development agency, Amahara National Regional Health Bureau, 2009

[10] WHO. Report of the Fifth Consultative Meeting on Leishmania/HIV Co-infection Addis Ababa, Ethiopia, 20-22 March, 2007.

[11] Mengistu M, Ayele B. Visceral Leishmaniasis and HIV co-infection in patients admitted to Gondar university hospital, northwest Ethiopia. Ethiop J Health Dev, vol. 21(1), pp. 53-60, 2007.

[12] Alvar J, Aparicio P, Aseffa A. The relationship between leishmaniasis and AIDS: the second 10 years. Clin Microbiol Rev, vol. 21, pp. 334-359, 2008.

[13] Anema A, Ritmeijer K. Treating HIV/AIDS and leishmaniasis co-infection in Ethiopia. JAMC, vol. 172(11), pp. 1434-1435, 2005.

[14] Berhe N. Hailu A, Wolday D, Negesse Y, Cenini P, Frommel D. Ethiopian visceral leishmaniasis patients co-infected with human immunodeficiency virus. Trans R Soc Trop Med Hyg, vol. 89 , pp. 205-207, 1995.

[15] Hailu A, Berhe N. The performance of direct agglutination test (DAT) in the diagnosis of visceral leishmaniasis among Ethiopian patients with HIV Co-infection. Ann Trop Med Parasitol, vol. 96(1), pp. 25-30, 2002.

[16] Ritmeijer K, Veeken H, Melaku Y, Leal G, Amsalu R, Seaman J, Davidson RN. Ethiopian kala-azar: generic sodium stibogluconate and Pentostam are equivalent; HIV co- infected patients have a poor outcome. Trans R Soc Trop Med Hyg , vol. 95(6), pp. 668-672, 2001. 
[17] Federal Democratic Republic of Ethiopia Population Census Commission: Summary and statistical Report of the 2007 Population and Housing Census: Population size by age and sex. Addis Ababa; 2008.
[18] Bashaye S, Nombela N, Argaw D, Mulugeta A, Herrero M, Nieto J, Chicharro C, Cañavate C, Aparicio P, Darío Vélez I, Alvar J, Bern C. Risk Factors for Visceral Leishmaniasis in a New Epidemic Site in Amhara Region, Ethiopia. Am J Trop Med Hyg, vol. 81 (1), pp. 32-39, 2009. 